\title{
MicroRNA-9 expression is a prognostic biomarker in patients with osteosarcoma
}

\author{
Shi-hong $\mathrm{Xu}^{1}$, Yong-liang Yang ${ }^{1}$, Shu-mei Han ${ }^{2}$ and Zong-hui $\mathrm{Wu}^{3^{*}}$
}

\begin{abstract}
Background: The purpose of the present study was to examine the expression levels of microRNA-9 (miR-9) in osteosarcoma tissues and normal bone tissues, and investigate the relationships between miR-9 expression, clinicopathological features and the prognosis of patients with osteosarcoma.

Methods: The expression levels of miR-9 in osteosarcoma tissues and corresponding non-cancerous tissues were detected using a real-time quantitative assay. Differences in patient survival were determined using the Kaplan-Meier method and a log-rank test. A Cox proportional hazards regression analysis was used for univariate and multivariate analyses of prognostic values.

Results: Compared to non-cancerous bone tissues, the expression levels of miR-9 in osteosarcoma tissues were significantly elevated $(P<0.001)$. We found that the expression level of miR-9 was significantly associated with tumor size $(P=0.011)$, clinical stage $(P=0.009)$ and distant metastasis $(P<0.001)$. The Kaplan-Meier curve showed that patients with low miR-9 expression survived significantly longer than patients with high miR-9 expression $(P=0.0017)$. Multivariate analysis suggested that miR-9 expression level $(P=0.002)$ is an independent prognostic factors for overall survival.

Conclusions: The findings of our study suggest that increased miR-9 expression has a strong correlation with the aggressive progression of osteosarcoma and its overexpression is a statistically significant risk factor affecting overall survival, suggesting that increased miR-9 expression could be a valuable marker of tumor progression and for prognosis of osteosarcoma.
\end{abstract}

Keywords: Osteosarcoma, MicroRNA-9, Prognosis

\section{Background}

Osteosarcoma is the most common primary malignancy in children and adolescents, accounting for 20 to $35 \%$ of all malignant primary bone tumors [1-3]. Although considerable advances in tumor excision technology, adjuvant chemotherapy and radiotherapy have significantly increased the survival rate of patients with osteosarcoma, the survival of osteosarcoma patients with lung metastasis and at an advanced clinical stage is quite poor [4]. A greater understanding of osteosarcoma is essential for developing novel approaches to increase survival rates. To our disappointment, despite the various efforts of basic research and clinical practice, the molecular

\footnotetext{
* Correspondence: dr_wuzonghui@126.com

${ }^{3}$ Department of ultrasound diagnosis, Shandong Medical Imaging Research Institute, Shandong University, 324 Jingwu Road, Jinan, Shandong Province 250021, China

Full list of author information is available at the end of the article
}

genetic mechanisms and the biology involved in osteosarcoma remain poorly understood [5].

MicroRNAs (miRNAs) are small non-coding RNA molecules that play an important role in the regulation of mRNA expression. miRNAs are known to be involved in various cellular processes and are associated with various diseases including cancer [6-8]. The association of altered microRNA expression with cancerogenesis as well as tumor progression is well established [9-11]. A growing number of microRNAs have been classified as oncogenes or tumor-suppressor genes. In addition, miRNA expression profiles and specific miRNAs have been shown to be potential diagnostic or prognostic tools for cancer [12-14].

Previous studies have found that miR-9 is downregulated in several cancers, including ovarian cancer, colon cancer, gastric cancer, renal cancer and esophageal cancer [15-19]. However, the expression of miR-9 has been found 
to be upregulated in biliary tract cancer, breast cancer, brain tumor and lung cancer [20-24]. These results suggest that miR-9 may play pivotal roles in tumorigenesis and tumor progression, and also exert different effects in various types of cancer. $\mathrm{Hu}$ et al. found that the expression level of miR-9 was increased in an osteosarcoma cell line compared with an osteoblast cell line [25]. However, the clinical significance of miR-9 in human osteosarcoma has not been investigated deeply. In the present study, we examined the expression levels of miR-9 in osteosarcoma tissues and normal bone tissues, and investigated the relationships between miR-9 expression, clinicopathological features and the prognosis of patients with osteosarcoma.

\section{Methods}

\section{Patients and tissue samples}

This study was approved by the Research Ethics Committee of Shandong Provincial Hospital affiliated to Shandong University. Written informed consent was obtained from all of the patients. All specimens were handled and made anonymous according to the ethical and legal standards. For quantitative real-time reverse-transcriptase-polymerase chain reaction (qRT-PCR) analysis, 79 patients with osteosarcomas and corresponding non-cancerous bone tissue samples from the same specimens were collected at Shandong Provincial Hospital affiliated to Shandong University from June 2006 to July 2012. No patients had received radiotherapy or chemotherapy before surgery. The clinical stage of these osteosarcoma patients was classified according to the sixth edition of the tumor-nodemetastases classification of the Union for International Cancer Control. The clinicopathological information of the patients is shown in Table 1.

\section{miRNA qRT-PCR assay}

The expression levels of miR-9 in osteosarcoma and corresponding non-cancerous tissues were detected using a qRT-PCR assay. Briefly, total RNA from tissue samples was extracted with TRizol reagent (Invitrogen, Breda, the Netherlands) according to the manufacturer's instructions. cDNA was reverse transcribed from total RNA samples using specific miRNA primers from the TaqMan MicroRNA Assays and reagents from the TaqMan MicroRNA Reverse Transcription kit (Applied Biosystems, Foster City, CA, USA) according to the manufacturer's instructions. Products were amplified by PCR using TaqMan Universal PCR Master Mix kit (Applied Biosystems). The quantitative PCR was performed with the specific primers as follows: miR-9_F, 5'-GTGCAGGGTCCGA GGT; miR-9_R, 5'-GCGCTCTTTGGTTATCTAGC-3'; U6_F, 5'-CTCGCTTCGGCAGCACA-3'; U6_R, 5'-A ACGCTTCACGAATTTGCGT-3'. Small nucleolar RNA U6 was used as an internal standard for normalization. The cycle threshold $\left(C_{T}\right)$ was calculated. The
Table 1 Correlation of miR-9 expression levels with clinicopathological features of patients with osteosarcoma

\begin{tabular}{|c|c|c|c|c|}
\hline \multirow{2}{*}{$\begin{array}{l}\text { Clinicopathological } \\
\text { features }\end{array}$} & \multirow{2}{*}{$\begin{array}{l}\text { Number } \\
\text { of cases }\end{array}$} & \multicolumn{2}{|c|}{ miR-9 expression } & \multirow[t]{2}{*}{$P$ value } \\
\hline & & High $(n, \%)$ & Low $(n, \%)$ & \\
\hline \multicolumn{5}{|l|}{ Age } \\
\hline$<50$ & 41 & $23(56.1 \%)$ & $18(43.9 \%)$ & 0.879 \\
\hline$\geq 50$ & 38 & 17 (44.7\%) & $21(55.3 \%)$ & \\
\hline \multicolumn{5}{|l|}{ Gender } \\
\hline Male & 44 & $25(56.8 \%)$ & $19(43.2 \%)$ & 0.636 \\
\hline Female & 35 & $15(42.9 \%)$ & $20(57.1 \%)$ & \\
\hline \multicolumn{5}{|l|}{ Anatomical location } \\
\hline Tibia/femur & 51 & $26(51.0 \%)$ & $25(49.0 \%)$ & 0.901 \\
\hline Elsewhere & 28 & $14(50.0 \%)$ & $14(50.0 \%)$ & \\
\hline \multicolumn{5}{|l|}{ Tumor size (cm) } \\
\hline$<8$ & 48 & 17 (35.4\%) & 31 (64.6\%) & \\
\hline$\geq 8$ & 31 & $23(74.2 \%)$ & $8(25.8 \%)$ & 0.011 \\
\hline \multicolumn{5}{|l|}{ Clinical stage } \\
\hline$|/| \mid$ & 39 & $9(23.1 \%)$ & $30(76.9 \%)$ & \\
\hline III & 40 & 31 (77.5\%) & $9(22.5 \%)$ & 0.009 \\
\hline \multicolumn{5}{|l|}{ Pathological fracture } \\
\hline Present & 11 & $6(54.5 \%)$ & $5(45.4 \%)$ & \\
\hline Absent & 68 & $34(50.0 \%)$ & $34(50.0 \%)$ & 0.899 \\
\hline \multicolumn{5}{|l|}{ Distant metastasis } \\
\hline Present & 19 & $17(89.5 \%)$ & $2(10.5 \%)$ & \\
\hline Absent & 60 & $21(35.0 \%)$ & 39 (65.0\%) & $<0.001$ \\
\hline
\end{tabular}

$2^{-\Delta \mathrm{CT}}\left(\Delta C_{T}=C_{T \text { miR-9 }}-C_{T \mathrm{U} 6 \mathrm{RNA}}\right)$ method was used to quantify the relative amount of miR-9. In addition, each measurement was performed in triplicate.

\section{Statistical analysis}

SPSS 13.0 statistical software (SPSS Inc, Chicago, IL, USA) was used for the statistical assay of all experimental data. Continuous variables were expressed as mean \pm standard deviation (SD). The paired $t$-test was used to evaluate the differences in miR-9 expression levels in osteosarcoma and corresponding non-cancerous bone tissues. The chi-square test was used to show differences in categorical variables. Differences in patient survival were determined by the Kaplan-Meier method and logrank test. A Cox proportional hazards regression analysis was used for univariate and multivariate analyses of prognostic values. A difference was considered statistically significant when $P<0.05$.

\section{Results}

Elevated expression of miR-9 in osteosarcoma tissues The expression levels of miR-9 in osteosarcoma and corresponding non-cancerous bone samples were detected by qRT-PCR and normalized to RNU6. Compared to 
non-cancerous bone tissues, the expression levels of miR-9 in osteosarcoma tissues were significantly elevated $(P<0.001$, Figure 1$)$. The relative level of miR-9 expression normalized to RNU6 in osteosarcoma tissues (mean \pm SD: $5.57 \pm 2.28)$ was significantly higher than that in corresponding non-cancerous bone tissues (mean $\pm \mathrm{SD}$ : $3.21 \pm 1.61$ ). The median of miR-9 expression levels in all 79 patients with osteosarcoma was 5.44. We divided the patients into two groups according to their expression levels of miR-9 using the median as a cutoff: high miR-9 expression group $(n=40$, mean \pm SD: $7.30 \pm 1.69)$ and low miR-9 expression group $(n=39$, mean \pm SD: $3.80 \pm 1.18)$.

\section{Correlation between clinicopathological features and miR-9 expression levels in osteosarcoma tissues}

To further delineate the possible roles of miR-9 in the development and progression of osteosarcoma, we conducted an investigation into the associations of miR-9 expression with clinicopathological features of the patients with osteosarcoma. Table 1 summarizes the associations of miR-9 expression with various clinicopathological parameters of the patients with osteosarcoma. We found that the expression level of miR-9 was significantly associated with tumor size $(P=0.011)$, clinical stage $(P=0.009)$ and distant metastasis $(P<0.001)$. In contrast, no association was found between the expression level of miR-9 with age $(P=0.879)$, gender $(P=0.636)$, anatomical location $(P=0.901)$ or pathological fracture $(P=0.899)$.

\section{MiR-9 expression is a prognostic biomarker in patients with osteosarcoma}

The correlation between miR-9 expression level and survival time of the patients with osteosarcoma was evaluated using Kaplan-Meier survival analysis. The Kaplan-Meier curve for overall survival regarding miR-9 expression level is shown in Figure 2. The curve shows that osteosarcoma

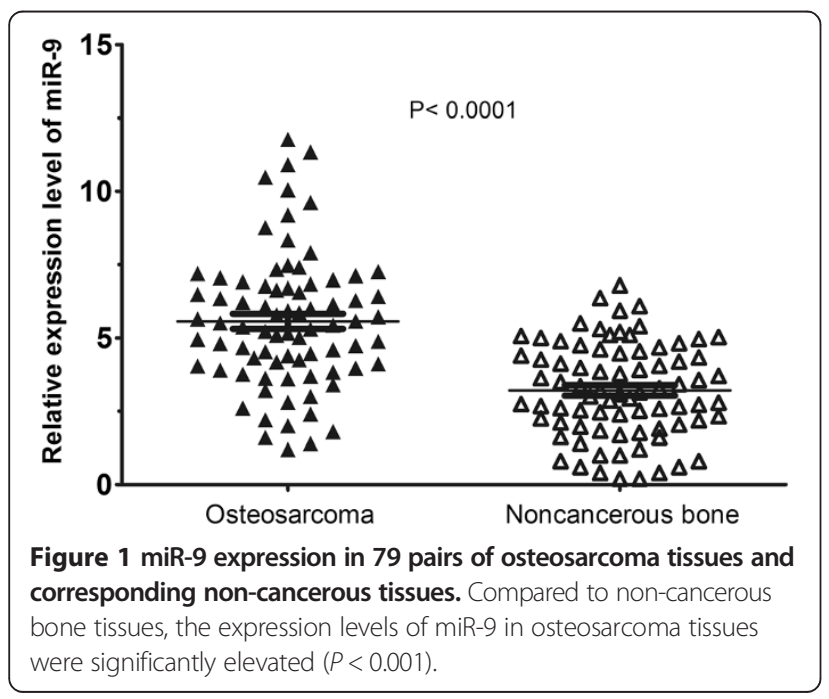

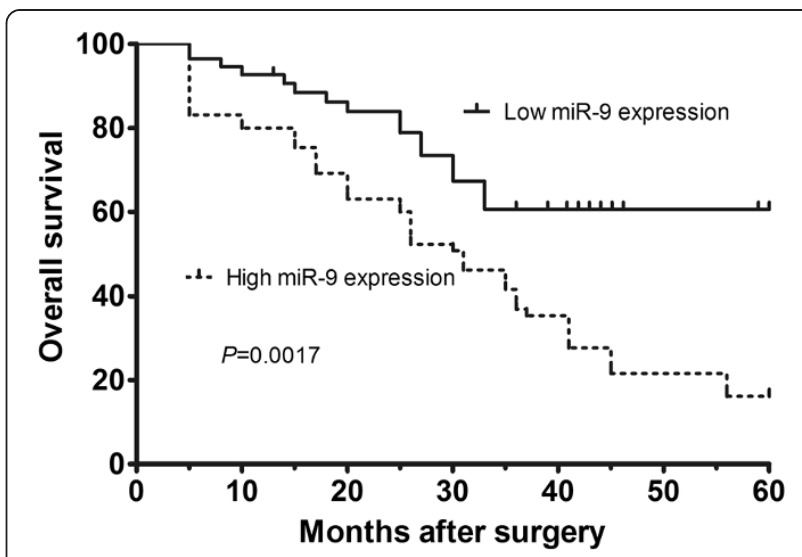

Figure 2 Kaplan-Meier survival curves for osteosarcoma patients with high or low expression of miR-9.

patients with low miR-9 expression in their tumor tissues survived significantly longer than patients with high miR-9 expression $(P=0.0017$, by log-rank test). For patients with high miR-9 expression, the 5-year overall survival was $16.2 \%$; however, the overall survival of patients with low miR-9 expression was $60.6 \%$. Multivariate analysis suggested that clinical stage $(P=0.01)$ and miR- 9 expression level $(P=0.002)$ were significant independent prognostic factors for overall survival (shown in Table 2).

\section{Discussion}

miRNAs are known to be involved in various cellular processes and are associated with various diseases including cancer. They can regulate gene expression at a posttranscriptional level and play a pivotal role in the regulation of cell development, metabolism, immunity, proliferation, differentiation and apoptosis. Published data shows that miRNAs are involved in carcinogenesis as either oncogenes or tumor suppressors and many cancer-related miRNAs have been identified functionally [26,27].

Many molecular markers have proven prognostic value for osteosarcoma. It would be helpful if these markers were used as objective instruments for predicting the

Table 2 Multivariate analysis of overall survival in patients with osteosarcoma

\begin{tabular}{llll}
\hline Parameter & Hazard ratio & $\begin{array}{l}\text { 95\% confidence } \\
\text { interval }\end{array}$ & P value \\
\hline Age & 1.06 & $0.62-2.98$ & 0.67 \\
Gender & 0.91 & $0.67-1.84$ & 0.53 \\
Anatomical location & 0.95 & $0.81-2.01$ & 0.79 \\
Tumor size (cm) & 2.56 & $0.91-5.39$ & 0.08 \\
Clinical stage & 3.31 & $1.93-6.77$ & 0.01 \\
Pathological fracture & 1.27 & $0.59-2.33$ & 0.49 \\
Distant metastasis & 4.01 & $0.98-10.89$ & 0.06 \\
miR-9 expression level & 4.77 & $2.86-5.91$ & 0.002 \\
\hline
\end{tabular}


chance of survival or chemotherapy response, especially early in treatment, preferably even before surgery. Previous studies have found that miR-9 is downregulated in several cancers, including ovarian cancer, colon cancer, gastric cancer, renal cancer and esophageal cancer [15-19]. However, the expression of miR-9 has been found to be upregulated in biliary tract cancer, breast cancer, brain tumor and lung cancer [20-24]. These results suggest that miR-9 may play pivotal roles in tumorigenesis and tumor progression, and also exert different effects in various types of cancer. In the present study, we found that miR-9 expression was increased in osteosarcoma tissues compared with non-cancerous bone tissues; further, the upregulation of miR-9 in osteosarcoma tissues was significantly correlated with aggressive clinicopathological features, including tumor size, clinical stage and distant metastasis. These findings suggested that a higher level of miR-9 expression may be involved in osteosarcoma pathogenesis and progression. Furthermore, we analyzed a correlation between miR-9 expression level and prognosis of osteosarcoma. Patients with high miR-9 expression had a shorter overall survival rate than those with low miR-9 expression. These findings were further supported by the multivariate analyses of a Cox proportional hazards regression model, suggesting that the level of miR-9 expression may be an independent factor for predicting the prognosis of patients with osteosarcoma. This was in agreement with previous studies that validated miR-9 as a novel prognostic biomarker for lung cancer, cervical cancer and glioma $[20,28,29]$.

Therefore, our data suggest that the high expression of miR-9 is associated with an increased risk of death from osteosarcoma. To our knowledge, this is the first study to investigate the clinical significance of miR-9 in patients with osteosarcoma. There are several possible causes for the dysregulation of miRNA profiling, including miR-9, in diverse carcinomas. miRNA expression is regulated by genetic and epigenetic factors. For instance, MYC/MYCN regulates the expression of miR-9 in breast cancer, and DNA methylation influences miR-9 expression in colorectal cancer $[21,30]$. Regarding the possible molecular mechanisms regulated by miR- 9 expression in human cancers, Ma et al. reported that miR-9 is a putative metastasis promoter in breast cancer. They demonstrated that miR-9 targeted CDH-1 mRNA, which encodes E-cadherin, leading to the scattering and EMT-like conversion of SUM149 cells. Ectopic expression of miR-9 downregulated the E-cadherin level, thus increasing the nuclear translocation of $\beta$-catenin, and enhanced its binding with transcription factors TCF/LEF to upregulate the transcription of genes that facilitate cell proliferation and angiogenesis [21]. Zheng et al. identified cyclin D1 and Ets1 as new targets of miR-9 in gastric cancer and demonstrated that miR-9 suppressed proliferation, invasion and metastasis
[15]. Guo et al. reported that miR-9 inhibited ovarian cancer cell growth through regulation of NF-kB1 [18]. In this study, we identified that miR-9 played an oncogenic role in osteosarcoma; however, the precise mechanism of miR-9 in osteosarcoma tumorigenesis and progression is still not understood.

\section{Conclusions}

In conclusion, the findings of our study suggest that increased miR-9 expression has a strong correlation with the aggressive progression of osteosarcoma and its overexpression is a statistically significant risk factor affecting overall survival in patients with osteosarcoma, suggesting that increased miR-9 expression could be a valuable marker of tumor progression and for prognosis of osteosarcoma. Further research is needed to clarify the exact mechanism of miR-9 in osteosarcoma.

\section{Abbreviations}

miRNA: microRNA; miR-9: microRNA-9; qRT-PCR: quantitative real-time reverse-transcription-polymerase chain reaction; SD: standard deviation.

\section{Competing interests}

The authors have no proprietary interest in any materials or methods described within this paper. This submission has not been published anywhere previously and it is not simultaneously being considered for any other publication.

\section{Authors' contributions}

$X S, Y Y, H S$ and WZ carried out the experiments, XS designed the study, XS and $Y Y$ prepared the manuscript. All authors read and approved the final manuscript.

\section{Acknowledgments}

We thank all the patients who were included in the present study.

\section{Author details}

'Department of Orthopedics, Shandong Provincial Hospital affiliated to Shandong University, Jinan, Shandong 250021, China. ${ }^{2}$ Department of Medicine, Shandong Cancer Hospital and Institute, Jinan, Shandong 250117, China. ${ }^{3}$ Department of ultrasound diagnosis, Shandong Medical Imaging Research Institute, Shandong University, 324 Jingwu Road, Jinan, Shandong Province 250021, China.

Received: 7 March 2014 Accepted: 12 June 2014

Published: 27 June 2014

\section{References}

1. Marina N, Gebhardt M, Teot L, Gorlick R: Biology and therapeutic advances for pediatric osteosarcoma. Oncologist 2004, 9:422-441.

2. Bielack SS, Marina N, Ferrari S, Helman LJ, Smeland S, Whelan JS, Reaman GH: Osteosarcoma: the same old drugs or more? J Clin Oncol 2008, 26:3102-3103. author reply 3104-3105.

3. Longhi A, Errani C, De Paolis M, Mercuri M, Bacci G: Primary bone osteosarcoma in the pediatric age: state of the art. Cancer Treat Rev 2006, 32:423-436

4. Messerschmitt PJ, Rettew AN, Brookover RE, Garcia RM, Getty PJ, Greenfield EM: Specific tyrosine kinase inhibitors regulate human osteosarcoma cells in vitro. Clin Orthop Relat Res 2008, 466:2168-2175.

5. Bacci G, Longhi A, Versari M, Mercuri M, Briccoli A, Picci P: Prognostic factors for osteosarcoma of the extremity treated with neoadjuvant chemotherapy: 15-year experience in 789 patients treated at a single institution. Cancer 2006, 106:1154-1161.

6. Filipowicz W, Bhattacharyya SN, Sonenberg N: Mechanisms of post-transcriptional regulation by microRNAs: are the answers in sight? Nature Rev Genet 2008, 9:102-114. 
7. van Kouwenhove M, Kedde M, Agami R: MicroRNA regulation by RNA-binding proteins and its implications for cancer. Nat Rev Cancer 2011, 11:644-656.

8. Chen X, Ba Y, Ma L, Cai X, Yin Y, Wang K, Guo J, Zhang Y, Chen J, Guo X, Li Q, Li X, Wang W, Zhang Y, Wang J, Jiang $X$, Xiang $Y$, Xu C, Zheng P, Zhang J, Li R, Zhang H, Shang X, Gong T, Ning G, Wang J, Zen K, Zhang J, Zhang CY: Characterization of microRNAs in serum: a novel class of biomarkers for diagnosis of cancer and other diseases. Cell Res 2008, 18:997-1006.

9. Esquela-Kerscher A, Slack FJ: Oncomirs - microRNAs with a role in cancer. Nat Rev Cancer 2006, 6:259-269.

10. Calin GA, Croce CM: MicroRNA-cancer connection: the beginning of a new tale. Cancer Res 2006, 66:7390-7394.

11. Zhang B, Pan $X$, Cobb GP, Anderson TA: microRNAs as oncogenes and tumor suppressors. Dev Biol 2007, 302:1-12.

12. Cho WC: OncomiRs: the discovery and progress of microRNAs in cancers. Mol Cancer 2007, 6:60.

13. He L, Thomson JM, Hemann MT, Hernando-Monge E, Mu D, Goodson S, Powers S, Cordon-Cardo C, Lowe SW, Hannon GJ, Hammond SM: A microRNA polycistron as a potential human oncogene. Nature 2005, 435:828-833.

14. Hayashita $Y$, Osada H, Tatematsu Y, Yamada H, Yanagisawa K, Tomida S, Yatabe Y, Kawahara K, Sekido Y, Takahashi T: A polycistronic microRNA cluster, miR-17-92, is overexpressed in human lung cancers and enhances cell proliferation. Cancer Res 2005, 65:9628-9632.

15. Zheng L, Qi T, Yang D, Qi M, Li D, Xiang X, Huang K, Tong Q: microRNA-9 suppresses the proliferation, invasion and metastasis of gastric cancer cells through targeting cyclin D1 and Ets1. PLOS ONE 2013, 8:e55719.

16. Hildebrandt MA, Gu J, Lin J, Ye Y, Tan W, Tamboli P, Wood CG, Wu X: Hsa-miR-9 methylation status is associated with cancer development and metastatic recurrence in patients with clear cell renal cell carcinoma. Oncogene 2010, 29:5724-5728.

17. Cekaite L, Rantala JK, Bruun J, Guriby M, Agesen TH, Danielsen SA, Lind GE, Nesbakken A, Kallioniemi O, Lothe RA, Skotheim RI: MiR-9, -31, and -182 deregulation promote proliferation and tumor cell survival in colon cancer. Neoplasia 2012, 14:868-879.

18. Guo LM, Pu Y, Han Z, Liu T, Li YX, Liu M, Li X, Tang H: MicroRNA-9 inhibits ovarian cancer cell growth through regulation of NF-kB1. FEBS J 2009, 276:5537-5546.

19. Hu Y, Correa AM, Hoque A, Guan B, Ye F, Huang J, Swisher SG, Wu TT, Ajani $J A, X u X C$ : Prognostic significance of differentially expressed miRNAs in esophageal cancer. Int J Cancer 2011, 128:132-143.

20. Xu T, Liu X, Han L, Shen H, Liu L, Shu Y: Up-regulation of miR-9 expression as a poor prognostic biomarker in patients with non-small cell lung cancer. Clin Transl Oncol 2013, 16(5):469-475.

21. Ma L, Young J, Prabhala H, Pan E, Mestdagh P, Muth D, Teruya-Feldstein J, Reinhardt F, Onder TT, Valastyan S, Westermann F, Speleman F, Vandesompele J, Weinberg RA: miR-9, a MYC/MYCN-activated microRNA, regulates E-cadherin and cancer metastasis. Nat Cell Biol 2010, 12:247-256.

22. Shigehara K, Yokomuro S, Ishibashi O, Mizuguchi Y, Arima Y, Kawahigashi $Y$, Kanda T, Akagi I, Tajiri T, Yoshida H, Takizawa T, Uchida E: Real-time PCR-based analysis of the human bile microRNAome identifies miR-9 as a potential diagnostic biomarker for biliary tract cancer. PLOS ONE 2011, 6:e23584.

23. Zhou X, Marian C, Makambi KH, Kosti O, Kallakury BV, Loffredo CA, Zheng YL: MicroRNA-9 as potential biomarker for breast cancer local recurrence and tumor estrogen receptor status. PLOS ONE 2012, 7:e39011.

24. Nass D, Rosenwald S, Meiri E, Gilad S, Tabibian-Keissar H, Schlosberg A, Kuker H, Sion-Vardy N, Tobar A, Kharenko O, Sitbon E, Lithwick Yanai G, Elyakim E, Cholakh H, Gibori H, Spector Y, Bentwich Z, Barshack I, Rosenfeld $\mathrm{N}$ : MiR-92b and miR-9/9* are specifically expressed in brain primary tumors and can be used to differentiate primary from metastatic brain tumors. Brain Pathol 2009, 19:375-383.

25. Hu H, Zhang Y, Cai XH, Huang JF, Cai L: Changes in microRNA expression in the MG-63 osteosarcoma cell line compared with osteoblasts. Oncol Lett 2012, 4:1037-1042.

26. Chen $X$, Gong J, Zeng $H$, Chen $N$, Huang $R$, Huang $Y$, Nie L, Xu M, Xia J, Zhao F, Meng W, Zhou Q: MicroRNA145 targets BNIP3 and suppresses prostate cancer progression. Cancer Res 2010, 70:2728-2738.

27. Pineau P, Volinia S, McJunkin K, Marchio A, Battiston C, Terris B, Mazzaferro V, Lowe SW, Croce CM, Dejean A: miR-221 overexpression contributes to liver tumorigenesis. Proc Natl Acad Sci U S A 2010, 107:264-269.
28. Wu Z, Wang L, Li G, Liu H, Fan F, Li Z, Li Y, Gao G: Increased expression of microRNA-9 predicts an unfavorable prognosis in human glioma. Mol Cell Biochem 2013, 384:263-268.

29. Hu X, Schwarz JK, Lewis JS Jr, Huettner PC, Rader JS, Deasy JO, Grigsby PW, Wang $X$ : A microRNA expression signature for cervical cancer prognosis. Cancer Res 2010, 70:1441-1448.

30. Vinci S, Gelmini S, Mancini I, Malentacchi F, Pazzagli M, Beltrami C, Pinzani P, Orlando C: Genetic and epigenetic factors in regulation of microRNA in colorectal cancers. Methods 2013, 59:138-146.

\section{doi:10.1186/1477-7819-12-195}

Cite this article as: Xu et al: MicroRNA-9 expression is a prognostic biomarker in patients with osteosarcoma. World Journal of Surgical Oncology 2014 12:195.

\section{Submit your next manuscript to BioMed Central and take full advantage of:}

- Convenient online submission

- Thorough peer review

- No space constraints or color figure charges

- Immediate publication on acceptance

- Inclusion in PubMed, CAS, Scopus and Google Scholar

- Research which is freely available for redistribution

Submit your manuscript at www.biomedcentral.com/submit
C Biomed Central 